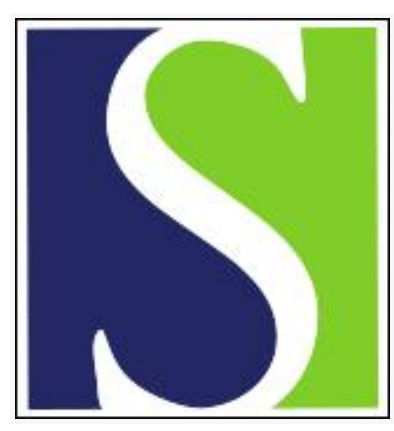

Scand J Work Environ Health 1980;6(2):146-152

https://doi.org/10.5271/sjweh.2621

Issue date: Jun 1980

\title{
Statistical modeling of epidemiologic data.
}

by Nurminen $\mathrm{M}$, Mutanen $\mathrm{P}$

Key terms: case-compeer study; case-control study; case-control study; contingency table; epidemiologic data; epidemiology; interaction; interaction association; long-linear model; rate ratio; statistical modeling; stratified analysis

This article in PubMed: www.ncbi.nlm.nih.gov/pubmed/7433950

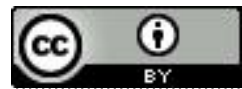




\title{
Statistical modeling of epidemiologic data ${ }^{1}$
}

\author{
by Markku Nurminen LSc, Pertti Mutanen, MSc ${ }^{2}$
}

\begin{abstract}
NURMINEN M, MUTANEN P. Statistical modeling of epidemiologic data. Scand $j$ work environ health 6 (1980) 146-152. The application of statistical modeling to epidemiology may help suggest a form for the mechanism of exposure action. But distinguishing between the entertained biological models is often difficult due to both inadequacies in epidemiologic studies and inaccuracies in the verbal specifications of the hypothesized interaction mechanisms. For example, the independent and interactive effects of asbestos and smoking on the production of lung cancer have not yet been fully established. In the present communication an analysis of illustrative data from a hypothetical case-compeer study was attempted with the estimation of rate ratios and the use of a log-linear model fitting technique. These analyses allow a parametric representation of the testable models. For adequate material they might provide tentative insight as to whether the data would conform more closely to an additive model than to a multiplicative one or to some other advocated pattern of action.
\end{abstract}

Key terms: case-compeer (case-control) study, contingency table, interaction (association), log-linear models, rate ratios, stratified analysis.

1 Definitions of terms used in this article: contingency table is a frequency table in which the contingent observation data are stratified by, ie, divided according to, two or more variables. First-order or two-factor interaction is the reciprocal action of a pair of qualitative variables forming a two-way contingency table; it is used synonymously with association. Second-order or threefactor interaction describes the mutual relationship of a triplet of variables in a threeway contingency table. Synergism (antagonism) is the simultaneous action of separate agents which, together, have a greater (less) total effect than the sum of their individual effects. A log-linear model postulates that the logarithm of the expected values of the observations in a contingency table are given by a linear combination of a number of parameters. Hierarchical model is such that, whenever a higher order effect is included in the model, the lower order effects composed from variables in the higher effect are also included.

2 Department of Epidemiology and Biometry, Institute of Occupational Health, Helsinki, Finland.

Reprint requests to: Mr Markku Nurminen, Department of Epidemiology and Biometry, Institute of Occupational Health, Haartmaninkatu 1, SF-00290. Helsinki 29, Finland.
Applying a statistical model to epidemiologic data to test old and generate new biological models for the interaction of disease agents has been found to be useful, $\mathrm{eg}$, in the specific area of carcinogenesis research (9). A known example of the problem at issue is the syncarcinogenesis of tobacco smoke and asbestos dust in the etiology of lung cancer.

At least three mechanisms (models) have been assumed to describe the existing epidemiologic data in asbestos-smoking interaction (7). In the first model the two factors act as independent causes and their joint effect is obtained if the reference category or base-line incidence rate of lung cancer is added to the excess over the base line due to asbestos. In addition the excess due to smoking can operate independently to produce lung cancer, but, when they occur together, their combined effect is synergistic, ie, more than additive. This model may be specified by different parametrizations. One with a wide applicability is constructed in a multiplicative fashion; the combined effect of the two factors is equal to the product of their 
separate independent effects (multiplicative model).

It should be noted that the meaning of statistical independence depends on the scale of measurement or, equivalently, on the chosen model. Thus, eg, independence under the multiplicative model would imply synergism under the additive model (on a linear scale). According to the third and more complex model, smoking is a cause of lung cancer, but asbestos exposure is a cause only when the smoking factor is also present, and their combined effect is (usually much) greater than that of smoking alone. In this situation smoking is necessary for the effect of asbestos. We have called this model "smoking-synergistic" with no "effect" for asbestos on its own.

The majority of existing evidence favors the multiplicative model, but the distinction between these models is subtle.

\section{Stratified analysis}

For simplicity we have chosen artificial data from a case-compeer (case-control) study with two dichotomous study variables as the example. Table 1 shows the illustrative data for all 1,000 cases stratified by the two factors under investigation (such as occurrence of asbestos fibers in the lungs and smoking history). These data would allow us to study the possible twoand three-factor interactions on the development of lung cancer.

When table 1 is collapsed over the smoking variable, the finding of larger numbers in the lungs of cancer cases than their compeers is highly significant at the $0.1 \%$ level $\left(\chi^{2}=31.8, \mathrm{df}=1\right)$. The rate ratio (RR) estimate can be calculated with the use of Bayes' theorem and prior information on the overall lung cancer rate (6); the RR estimate is calculated to be 2.3 . The proportion of deaths from lung cancer (ICD 162) was, eg, in Finland in 1966, only $1.6 \%$ of all deaths; therefore the exposureodds ratio (a measure not utilizing available information for the overall rate) closely approximates the corresponding ratio of posterior lung cancer rates (given exposure). The $95 \%$ confidence limits for this RR can be based on the value of the chi-square statistic used in significance testing (4); these limits are computed to be 1.7 and 3.1, which would indicate again the clear statistically significant increase in rate. The association between smoking habit and lung cancer is statistically highly significant $\left(\chi^{2}=154.1\right.$, df $\left.=1, p<0.001\right)$. The corresponding $R R$ estimate is 8.1 (5.811.3).

Table 1. Distribution of the lung cancer and compeer cases by occurrence of asbestos fibers in the lungs and smoking habits a and the rate estimates for different exposure categories.

\begin{tabular}{|c|c|c|c|c|c|}
\hline \multirow[b]{3}{*}{$\begin{array}{l}\text { Lung cancer cases } \\
\text { Compeer cases }\end{array}$} & \multicolumn{2}{|c|}{$\begin{array}{l}\text { Asbestos fibers } \\
\text { present }\end{array}$} & \multicolumn{2}{|c|}{$\begin{array}{c}\text { Asbestos fibers } \\
\text { absent }\end{array}$} & \multirow{2}{*}{ Total } \\
\hline & Smokers & $\begin{array}{l}\text { Non- } \\
\text { smokers }\end{array}$ & Smokers & $\begin{array}{l}\text { Non- } \\
\text { smokers }\end{array}$ & \\
\hline & $\begin{array}{l}370 \\
200\end{array}$ & $\begin{array}{r}30 \\
120\end{array}$ & $\begin{array}{l}90 \\
90\end{array}$ & $\begin{array}{l}10 \\
90\end{array}$ & $\begin{array}{l}500 \\
500\end{array}$ \\
\hline $\begin{array}{l}\text { Estimate of the } \\
\text { exposure category } \\
\text { specific rate b } \\
\text { Estimate of rate } \\
\text { ratio c }\end{array}$ & $\begin{array}{l}2.92 \% \\
16.2\end{array}$ & $\begin{array}{l}0.40 \% \\
2.2\end{array}$ & $\begin{array}{l}1.60 \% \\
8.9\end{array}$ & $\begin{array}{l}0.18 \% \\
1.0\end{array}$ & \\
\hline 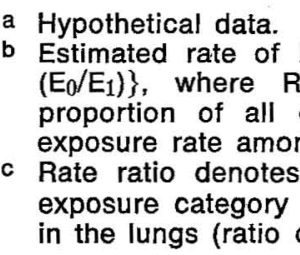 & $\begin{array}{l}\text { lung cancer } \\
=1.6 \% \\
\text { deaths, } E_{1}= \\
\text { ig compeers } \\
\text { the ratio } \\
\text { to the rate } \\
\text { of correspon }\end{array}$ & $\begin{array}{l}\text { (posterior } \\
\text { equals ov } \\
=\text { exposure } \\
\text { of the rate } \\
\text { among no } \\
\text { ding poste }\end{array}$ & $\begin{array}{l}\text { probability) } \\
\text { rall rate } \\
\text { rate amor } \\
\text { among tho } \\
\text { smokers wi } \\
\text { ior probabil }\end{array}$ & $\begin{array}{l}=1 /\{1+ \\
\text { of lung } \\
\text { g cases, } \\
\text { se in the } \\
\text { thout asbe } \\
\text { ities). }\end{array}$ & $\begin{array}{l}-R) / R] \\
\text { er, ie, } \\
E_{0}= \\
\text { mbined } \\
\text { fibers }\end{array}$ \\
\hline
\end{tabular}


Table 2. Percentage distribution of the lung cancer and compeer cases by smoking habits and occurrence of asbestos fibers in the lungs and the results of the significance and effect estimation.

\begin{tabular}{|c|c|c|c|c|}
\hline & \multicolumn{2}{|c|}{ Smokers } & \multicolumn{2}{|c|}{ Nonsmokers } \\
\hline & $\begin{array}{c}\text { Asbestos } \\
\text { fibers } \\
\text { present }\end{array}$ & $\begin{array}{c}\text { Asbestos } \\
\text { fibers } \\
\text { absent }\end{array}$ & $\begin{array}{l}\text { Asbestos } \\
\text { fibers } \\
\text { present }\end{array}$ & $\begin{array}{c}\text { Asbestos } \\
\text { fibers } \\
\text { absent }\end{array}$ \\
\hline \multirow[t]{2}{*}{$\begin{array}{l}\text { Lung cancer cases } \\
\text { Compeer cases }\end{array}$} & $\begin{array}{l}80 \% \\
69 \%\end{array}$ & $\begin{array}{l}20 \% \\
31 \%\end{array}$ & $\begin{array}{l}75 \% \\
57 \%\end{array}$ & $\begin{array}{l}25 \% \\
43 \%\end{array}$ \\
\hline & \multicolumn{2}{|c|}{$\begin{array}{l}\chi^{2}=12.8 \\
d f=1 \\
p<0.001\end{array}$} & \multicolumn{2}{|c|}{$\begin{array}{l}\chi^{2}=4.5 \\
\text { df }=1 \\
p<0.05\end{array}$} \\
\hline
\end{tabular}

Table 3. Percentage distribution of the lung cancer and compeer cases by occurrence of asbestos fibers in the lungs and smoking habits and the results of the significance testing and effect estimation.

\begin{tabular}{|c|c|c|c|c|}
\hline & \multicolumn{2}{|c|}{$\begin{array}{l}\text { Asbestos fibers } \\
\text { present }\end{array}$} & \multicolumn{2}{|c|}{$\begin{array}{c}\text { Asbestos fibers } \\
\text { absent }\end{array}$} \\
\hline & Smokers & $\begin{array}{c}\text { Non- } \\
\text { smokers }\end{array}$ & Smokers & $\begin{array}{c}\text { Non- } \\
\text { smokers }\end{array}$ \\
\hline \multirow[t]{2}{*}{$\begin{array}{l}\text { Lung cancer cases } \\
\text { Compeer cases }\end{array}$} & $\begin{array}{l}92 \% \\
62 \%\end{array}$ & $\begin{array}{r}8 \% \\
38 \%\end{array}$ & $\begin{array}{l}90 \% \\
50 \%\end{array}$ & $\begin{array}{l}10 \% \\
50 \%\end{array}$ \\
\hline & \multicolumn{2}{|c|}{$\begin{array}{l}\chi^{2}=97.0 \\
\text { df }=1 \\
p<0.001\end{array}$} & \multicolumn{2}{|c|}{$\begin{array}{l}\chi^{2}=44.8 \\
d f=1 \\
p<0.001\end{array}$} \\
\hline
\end{tabular}

As noted by Saracci (8) in a review of epidemiologic studies, a necessary condition for data to follow a multiplicative model is the constancy of RR due to asbestos for both smoking categories. The smokers' highly significant $R R$ of 1.8 $(1.3-2.5)$ is fairly close to that estimated for the nonsmokers $[\mathrm{RR}=2.2(1.1-4.6)]$, a finding which would demonstrate that smoking did not amplify the magnitude of the estimate of the effect of the asbestos factor. It is also evident from an inspection of the percentage distribution given in table 2.

Table 3 shows the percentage distribution of the lung cancer and compeer cases by occurrence of asbestos fibers in the lungs and smoking habits. The smokers' $\mathrm{RR}$ of lung cancer is 7.4 (5.0-11.0) among cases with asbestos fibers, but again an estimate of nearly the same magnitude is obtained among those cases without asbestos fibers [RR is $9.0(4.7-17.1)]$.
Next we have further examined the relative adequacies of the compared models with reference to the imaginary data in table 1.

Estimates of the RR of lung cancer for the combination of smoking habit and the finding of asbestos fibers in the lungs can be derived from the estimated exposure category-specific rates of cases and compeers, again via Bayes' theorem. These RRs (posterior probabilities) are shown in the lower part of table 1. Non-smokers without asbestos fibers in their lungs are the reference category. In the quantitation of interaction, a convenient index development by Rothman (7) is "the ratio of the observed effect with combined exposure to that effect expected with independently acting causes operating jointly." This is an index of synergism if its value exceeds one and of antagonism if less than one; if equal to one it represents causes acting independently. The 
relative excess risk associated with the presence of asbestos fibers, obtained by subtracting the reference category $R R$, is $2.2-1.0=1.2$. Similarly, the excess risk attributable to smoking is 7.9. Cases with both exposures have a relative excess risk of 15.2 , whereas $1.2+7.9=9.1$ would be expected if these causes acted independently. The point estimate of the index of interaction is $15.2 / 9.1=1.67$, indicating some amount of synergism and departure from the additive model. An approximate $95 \%$ interval estimate can be obtained for this index if the upper and lower limit is considered to be (7):

$$
\exp [\log (1.67) \pm 1.96(\mathrm{SE}) / 1.67]
$$

based on a log-Gaussian sampling distribution. The standard error (SE) of the index is approximated with the use of Woolfian type estimators for the sample variances and covariances of the categoryspecific RRs. We obtain an interval of $0.8-3.4$; thus in our example we can not be very confident that synergism actually exists, because the interval includes the value 1. For small numbers this method yields unstable estimates.

If interaction were assessed with the multiplication of the RRs as the criterion, these data would suggest a somewhat weaker than multiplicative effect, since the $\mathrm{RR}$ expected would be $2.24 \times 8.9=$ 19.9 , whereas an RR of only 16.2 was observed. The ratio of observed $R R$ to expected RR (0.81) measures the joint effect, in a multiplicative sense, of smoking and asbestos. (This ratio could equivalently be obtained if the smokers' RR were divided with that of the nonsmokers in table 2.) Since this ratio produced a value of slightly less than one, the two factors cannot be said to exert fully independent multiplicative effects in producing lung cancer.

Under the additive model we can, instead, expect an RR of 10.1 for the joint effect of these two carcinogens. Hence we might conclude that the data conform more likely to a multiplicative model than to the additive one and that the amount of synergism present very probably lies in a closer proximity to independence under the multiplicative model than under the additive model.

The incompatibility of the contingent data with the smoking-synergistic model is seen in that the RR for the nonsmoking cases with asbestos fibers in the lungs was 2.2 instead of the hypothesized value of 1.0. This model is nonspecific in that it merely states the existence, and not the degree, of synergism. In other words, it is only supposed that the $R R$ for cases with both exposures is greater than that for those who only smoked. The model does not specify, eg, that the combined exposure category-specific $R R$ of 16.2 should be twice as large as that of the smoking cases with no trace of asbestos exposure (8.9).

Since none of the three competing models seemed to be fully capable of explaining the interrelations in the made-up data, a more formal manner of model specification and a more systematic approach to model search was deemed desirable.

\section{Log-linear analysis}

We have reanalyzed the data using a loglinear model fitting and testing technique (5). These models rely upon a particular approach to the definition of interaction between or among variables in multidimensional contingency tables; the expected cell values of the table are simply the product of marginal probabilities. As a result, the models are linear on a logarithmic scale - hence the label log-linear models. An algorithm in Standard Fortran for the estimation of the expected cell frequencies with the iterative scaling procedure is given by Haberman (2).

In hierarchical log-linear models for complete contingency tables the logarithm of the expected values ( $\log$ F) of the frequencies of the factorial table is assumed to satisfy an additive model similar to that encountered in an analysis of variance. In a fully parametrisized model, for our example of a $2 \times 2 \times 2$ table,

$\log \mathrm{F}=\mathrm{M}+\mathrm{C}+\mathrm{S}+\mathrm{A}+\mathrm{CS}+\mathrm{CA}+\mathrm{SA}+\mathrm{CAS}$, where $\mathrm{M}=$ overall mean, $\mathrm{C}=$ main effect of variable "caseness," $\mathrm{S}=$ main effect of variable "smoking," $\mathrm{A}=$ main effect of variable "asbestos," CS = caseness-smoking interaction effect, $\mathrm{CA}=$ caseness-asbestos interaction effect, $\mathrm{AS}=$ asbestos- 
Table 4. Analysis of the deviance for interaction between lung cancer, asbestos fibers in the lungs and smoking habits.a

\begin{tabular}{rlccc}
\hline Number & Model terms b, c & $\begin{array}{c}\text { Devianced } \\
\mathrm{G}^{2}\end{array}$ & $\begin{array}{c}\text { Degrees of } \\
\text { freedom }\end{array}$ & p-value \\
\hline 0 & CA, CS, AS, CAS $\mathrm{f}$ & 0 & 0 & NS \\
1 & CA, CS, AS g & 0.2 & 1 & $<0.025$ \\
2 & CA, CS g & 8.0 & 2 & $<0.001$ \\
3 & CA, AS & 150.8 & 2 & $<0.001$ \\
4 & CS, AS & 17.3 & 2 & $<0.001$ \\
5 & CA & 173.6 & 3 & $<0.001$ \\
6 & CS & 40.1 & 3 & $<0.001$ \\
7 & AS & 182.9 & 3 & $<0.01$ \\
8 & C, A, S h & 205.7 & 4 & $<0.01$ \\
9 & CS, CAS i & 9.4 & 2 & 1 \\
10 & CA, CS, CAS j & 7.4 & 1 & 0.001 \\
\hline
\end{tabular}

a Derived from the illustrative data of table 1.

b $\mathrm{C}=$ Cancer/compeer case, $\mathrm{A}=$ asbestos fibers present/absent in the lungs, $\mathrm{S}=$ smoking habits (smoker/nonsmoker).

c Each model contains the configurations (terms) which are hypothesized as necessary in order to obtain the maximum likelihood estimates which fit the observed data well. The main effect terms $\mathrm{C}, \mathrm{A}$, and $\mathrm{S}$ and the general mean are included in each model. For example, the configuration CA includes the observed counts in the table which relates lung cancer to asbestos fibers in the lungs.

d The degrees of freedom associated with each effect depend on the number of categories in the relevant variables.

e Maximum difference between observed and fitted marginal totals was 0.1 .

f Saturated model (ie, fully parametrisized).

g Hierarchical, multiplicative type model.

h Minimal model (ie, main effects only).

i Nonhierarchical, smoking-synergistic model.

j Nonhierarchical, three-factor interaction model.

smoking interaction effect, and CAS $=$ caseness-asbestos-smoking interaction effect. Thus each main or interaction effect is represented by a term in the log-linear model.

An array of models is developed that exhausts the possible hypotheses of causal relations among the variables (table 4). Given each hypothesis, the expected distribution of the data is tested for goodnessof-fit with the "observed" distribution of the data (table 1) with a chi-square distributed statistic ( -2 times), the maximized log-likelihood ratio (termed deviance and represented symbolically by $\mathrm{G}^{2}$ ). A comparison of two models, one which includes the interaction (or effect) under investigation and one which does not, allows the contribution of the study variable to be tested.

Our primary interest in testing the departure from the additivity of effects was whether the multiplicative type of model (model 2 in table 4), which contained the associations of both asbestos and smoking with lung cancer, would provide an accurate description of the data. For completeness all hierarchical models were fitted to the data. A hierarchical model may be described in terms of the marginal totals to be fit. Additional nonhierarchical models were tried in order to test the tenability of the possibility that the three-factor interaction lung cancerasbestos-smoking (comparison of model 6 with 9 and model 10 with 2 in table 4) would be necessary to describe the distribution of numbers in each cell of the contingency (table 1). This action is equivalent to hypothesizing that in the presence of asbestos fibers the risk of lung cancer is raised more for smokers than for nonsmokers. Or conversely that smoking has a greater effect, in terms of increase in lung cancer incidence, among persons with than without asbestos fibers in their lungs.

The results of the analysis of deviance are shown in table 4. Only the multiplicative type of hierarchical model 1 provided a good fit to the data. In fact this model 
Table 6. Estimated frequencies, obtained from the fitting of a multiplicative type of model a to the data of table 1 , and rate estimates.

\begin{tabular}{|c|c|c|c|c|c|}
\hline \multirow[b]{3}{*}{$\begin{array}{l}\text { Lung cancer cases } \\
\text { Compeer cases }\end{array}$} & \multicolumn{2}{|c|}{$\begin{array}{c}\text { Asbestos fibers } \\
\text { present }\end{array}$} & \multicolumn{2}{|c|}{$\begin{array}{c}\text { Asbestos fibers } \\
\text { absent }\end{array}$} & \multirow{2}{*}{ Tota } \\
\hline & Smokers & $\begin{array}{l}\text { Non- } \\
\text { smokers }\end{array}$ & Smokers & $\begin{array}{c}\text { Non- } \\
\text { smokers }\end{array}$ & \\
\hline & $\begin{array}{l}371.1 \\
198.9\end{array}$ & $\begin{array}{r}28.9 \\
121.1\end{array}$ & $\begin{array}{l}88.9 \\
91.1\end{array}$ & $\begin{array}{l}11.1 \\
88.9\end{array}$ & $\begin{array}{l}500 \\
500\end{array}$ \\
\hline $\begin{array}{l}\text { Estimare of the } \\
\text { exposure category } \\
\text { specific rate } \\
\text { Estimate of rate } \\
\text { ratio }\end{array}$ & $\begin{array}{l}2.94 \% \\
14.7\end{array}$ & $0.39 \%$ & $1.56 \%$ & $\begin{array}{l}0.20 \% \\
1.0\end{array}$ & \\
\hline
\end{tabular}

a Model 1 of table 4.

state that asbestos and smoking are independently capable of producing lung cancer, but with constant RRs in each category of the other factor, and that the finding of asbestos fibers in the lungs and smoking history were (noncausally) linked in these data.

Greenland (3) has cautioned against an uncritical use of log-linear (or logistic) models for the multivariate analysis of epidemiologic data. His criticism was pointed at "exclusive use of one particular model" when additivity holds, since as "log-linear models imply a multiplicative statistical relationship between the effects of the study exposures," it can lead to interpretational difficulties.

We have attempted to clarify these interpretational pitfalls by supplementing the log-linear analysis with the analysis by $R R$ employing, among others, the relative excess risk parameter. This dual approach is desirable as the quantitated relationship seldom conforms perfectly to either a multiplicative model or to an additive one. Moreover, the chosen model yielded cell estimates that were more stable than the "observed" three-way table frequencies, and these fitted estimates allowed us to quantitate the effects of the study variables and interactions between them in terms of exposurespecific rates and RRs. In the oversimplified case of the imaginary data, it was easy to test all the possible hierarchical models and also the previously advocated nonhierarchical ones. Thus, the danger of "the inadvertant ex- clusion from consideration of other, possibly more appropriate models for disease risk [3]" was small. In a more complicated real-life situation with multiple continuous and discrete variables (both matched and unmatched), a number of strategies can be chosen for the statistical problem of model selection [such as those discussed by Beneditti \& Brown (1)].

\section{References}

1. Benedetti JK, Brown MB. Strategies for the selection of log-linear models. Biometrics 34 (1978) 680-686.

2. Haberman SJ. Log-linear fit for contingency tables: Algorithm AS 51. Appl stat 21 (1972) 218-225.

3. Greenland S. Limitations of the logistic analysis of epidemiologic data. Am $j$ epidemiol 110 (1979) 693-698.

4. Miettinen OS. Simple interval estimation of risk ratio. Am j epidemiol 100 (1974) $515-516$.

5. Nelder JA, Wedderburn RWM. Generalized linear models. J r stat soc A 135 (1972) $370-384$.

6. Neutra RR, Drolette ME. Estimating exposure-specific disease rates from case-control studies using Bayes' theorem. Am j epidemiol 108 (1978) 214-221.

7. Rothman KJ. Synergy and antagonism in cause-effect relationships. Am $\mathrm{j}$ epidemiol 99 (1974) 385-388.

8. Saracci R. Asbestos and lung cancer: Anal$y$ sis of the epidemiologic evidence in the asbestos-smoking interaction. Int $\mathbf{j}$ cancer 20 (1977) 323-331.

9. Whittemore A, Keller JB. Quantitative theories. of carcinogenesis. SIAM rev 20 (1978) $1-30$. 